\title{
Incidence and clinico- anatomical relevance of pneumosinus dilatans frontalis using computed tomography and in south Indian skulls
}

\author{
Aftab Begum ${ }^{1}$, Siraj A. Shirbadgi ${ }^{2}$,* \\ ${ }^{1}$ Assistant Professor, Dept. of Physiology, ${ }^{2}$ Associate Professor, Dept. of Anatomy, Basaveshwara medical college and Hospital, \\ Chitradurga, Karnataka, India
}

*Corresponding Author:

Email: drsms70@gmail.com

Received: $23^{\text {rd }}$ February, 2018

Accepted: $24^{\text {th }}$ March, 2018

\begin{abstract}
Introduction: Pneumosinus dilatans (PD) is a rare craniofacial malformation characterized by unusual hyperaeration of any one of the paranasal sinuses. The etiology and pathogenesis of this condition remain unclear. Here we are presenting a case study on the incidence of Pneumosinus Dilatans Frontalis (PDF) using computed tomography and in south Indian skulls.

Materials and Methods: The present study was carried out in 92 dried adult human skull of unknown sex obtained from Department of Anatomy and 120 patients underwent paranasal sinus Computed tomography (CT) for various reasons at Bhasaweshwara Medical college and hospital, Chitradurga, Karnataka. The incidence of unilateral and bilateral PDF was observed and photographed.

Results: Out of 90 dried skulls, the incidence of unilateral PDF was found in only one case (1.09\%). In the present study, the incidence of bilateral PDF was not found in dried skulls. A total of 120 (240 slices) CT scans of the nose and paranasal sinuses were reviewed. We observed 3 cases $(2.5 \%)$ of bilateral PDF among them 2 cases were seen in males and one case in female.

Conclusions: PD is rare craniofacial deformity affects all paranasal sinus but most commonly affects the frontal sinus. Hence, a detailed anatomical and morphometric knowledge of the region is necessary to perform the successful surgeries and outcome in the region.
\end{abstract}

Keywords: Frontal sinus, paranasal sinus, Pneumosinus dilatans, Pneumosinus dilatans frontalis.

\section{Introduction}

Pneumosinus dilatans (PD) is a rare craniofacial malformation characterized by unusual hyperaeration of any one of the paranasal sinuses. In the literature, many terms were used to describe the same clinical condition as pneumocele, pneumosinus frontalis, sinus hypertrophy, aerocele, and hyper pneumatization. ${ }^{1}$ The disease was first described by Meyes but however, Benjamin (1918) coined the term Pneumosinus dilatans. ${ }^{2,3}$ Afroze (2017) was first who coined the term "Deer Horn Sinus" for Pneumosinus dilatans Frontalis (PDF) because on coronal computed tomography (CT) images PDF may give an appearance of deer horn. ${ }^{4} \mathrm{~A}$ systemic review conducted by Ricci JA et al (2017) has stated that PD most often involves frontal sinus and most commonly affects young adult males, followed by sphenoid sinus, ethmoid sinus and maxillary sinus. ${ }^{5-7}$

So far very few case reports or case series was documented because PD is often unexpected radiological findings. No research studies are available on PD. Ricci JA et al conducted an extensive review of the literature and documented that a total of 134 cases had reported in 117 articles. ${ }^{5}$ Here we are presenting a research study on the incidence of Pneumosinus Dilatans Frontalis (PDF) using computed tomography and in skulls of mostly south Indian individuals. The etiology and pathogenesis of this condition remain unclear.

\section{Materials and Methods}

The present study was carried out in 92 dried adult human skull of unknown sex obtained from Department of Anatomy and 120 patients underwent paranasal sinus Computed tomography (CT) for various reasons at Bhasaweshwara Medical college and hospital, Chitradurga, Karnataka. Each skull and CT images were observed for the presence of Pneumosinus Dilatans Frontalis (PDF). Representative photograph of PDF was taken using a digital camera.

\section{Exclusion criteria:}

1. Subjects whose CT images showed any disparity of paranasal sinuses anatomy due to surgery.

2. Subjects whose CT images showed any disparity of paranasal sinuses anatomy due to trauma.

3. Skulls with bilateral damaged frontal sinus were excluded from the study.

4. And the Skulls of younger individuals where frontal sinuses was not well formed.

The CT images and data obtained were performed according to the standard protocol of the volume mode. The study was done to all patients using TOSHIBA Aquilion 16 slice CT scanner with 512 elements, $256 \mathrm{x}$ 256 matrix. The technical parameters adopted for collection of data include a $120 \mathrm{kV}$ tube voltage and 150 effective $\mathrm{mAs}, 1$ second rotation time, section thickness of $1 \mathrm{~mm}$, a field of view (FOV) of $25 \mathrm{~cm}$. 


\section{Results}

90 adult dried human skulls were studied and analyzed for the occurrence of unilateral and as well as bilateral incidence of PDF. Out of 90 dried skulls, the incidence of unilateral Pneumosinus Dilatans Frontalis (PDF) was found in only one case (1.09\%) (Fig. 1). In the present study, the incidence of bilateral PDF was not found in dried skulls.

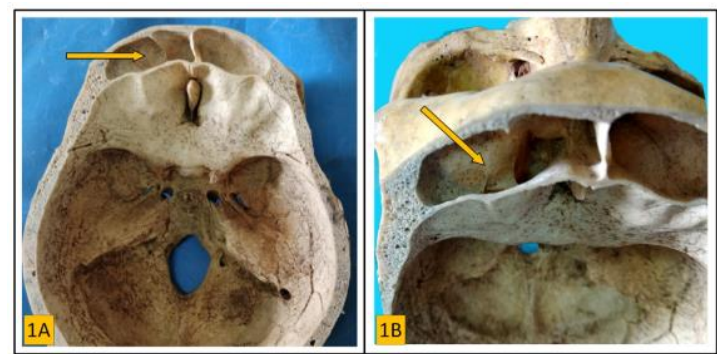

Fig. 1: Shows the Left unilateral PDF.

Pneumatization of frontal sinus involving the orbital plate of frontal bone

A total of 120 (240 sides) CT scans of the nose and paranasal sinuses were reviewed. Among them 86 were males and 34 were females, age ranging between 16-68 years (mean $\pm \mathrm{SD}, 43.64 \pm 9.34$ years). We observed 3 cases $(2.5 \%)$ of bilateral PDF among them 2 cases were seen in males and one case in female (Figure 2). In the present study, we have not documented the unilateral PDF in CT scan images.

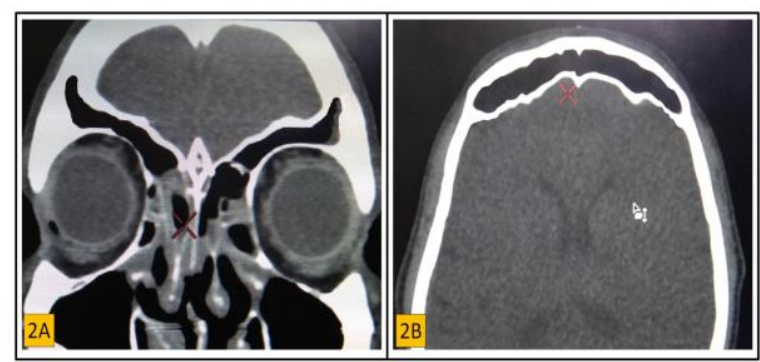

Fig. 2: shows the bilateral PDF, A) Coronal view B) Axial view. Pneumatization of frontal sinus involving the squamous part of the frontal bone.

On coronal CT images, pneumatization extends upto the parietal bone because of involvement of squamous part of the frontal bone. But PDF observed in dried skull shows the pneumatization involves the orbital part of the frontal bone.

\section{Discussion}

Pneumosinus Dilatans Frontalis (PDF) is a rare deformity of the craniofacial skeleton characterized by unusual hyperaeration of frontal sinus beyond the normal dimensions. The hyperaeration may involve complete or part of the sinus. In 1987, Urken et al classified paranasal sinus pneumatic dilations into three categories based on hyperaeration of the paranasal sinuses and degree of deviations from the normal sinus anatomy: 1) hyperpneumatization: sinus enlargement within the normal anatomical limits; 2) Pneumosinus dilatans: sinus enlargement beyond the normal anatomical limits; and 3) Pneumocele: sinus enlargement beyond the normal limits and causes erosion of the surrounding bony walls. ${ }^{8}$

Pneumatization of paranasal sinus begins during the second and fourth month of intrauterine life as evaginations of the epithelial cells from the nasal cavity. The Only sinus which is rudimentary or appears after birth among the entire paranasal sinus is frontal sinus. Pneumatization of frontal bone even continues after birth and completed after puberty. ${ }^{9}$ The dimension of the frontal sinus has been documented in the literature. A study conducted by Rubira-Bullen et al concluded that the height of the frontal sinus may vary between 7 and $65 \mathrm{~mm}$ and the width between 5 and $125 \mathrm{~mm} .{ }^{10}$

Multiple authors conducted an extensive review of PD offers a sum number of previously reported cases. In the literature, we found that PD had been documented radiographically, ${ }^{11}$ as clinical case reports, ${ }^{12,13}$ and few conducted as cadaveric study., Tellado et al in 2002 cited a 1968 review by Lombardi et al. The review by Lombardi et al includes 51 cases of PD, among them 39 cases in frontal sinus and 12 cases in another sinus. ${ }^{12}$ Ricci JA et al stated that incidence of PD roughly a single case reported per year. ${ }^{5}$ No case report or research study was acknowledged the incidence of PDF on dried skulls. Our study is the first to document the incidence of PDF in dried adult human skulls of south Indian origin. The incidence of unilateral PDF in our study was $1.09 \%$ (Fig. 1) whereas the incidence of bilateral PDF was not found in dried skulls. The incidence of bilateral PDF using CT was $2.5 \%$ among them 2 cases were seen in males and one case in the female.

Frontal bone has got two main parts, first squamous part and seccond Orbital part. Hyperaeration or pneumatization may be involved in any part of the frontal bone. According to Afroze et al pneumatization may extend upto the parietal bone if squamous part of frontal bone involves and it may extend upto sphenoid bone if the orbital part of frontal bone involves. He also stated that on coronary CT images may give an appearance of deer horn if pneumatization of frontal sinus involves parietal bone also. ${ }^{4}$ In the present study, the involvement of squamous part of the frontal bone was seen in CT images (Figure 2) whereas involvement of orbital part of frontal bone in the dried skull (Fig. 1) was observed.

Many theories have been postulated by various authors but still, the etiology and pathogenesis of this condition remain unclear. In the literature, we found the six possible or potential etiologies like ball-valve 
mechanism, fibro-osseous dysregulation, draining mucocele of frontal sinuses, hormonal cause, gas forming bacteria, congenital cause, and even trauma or surgery which may lead to this pathogenesis. ${ }^{5}$ Among above said etiologies, the most commonly accepted theory is the ball-valve mechanism. This mechanism put forward an idea that the expansion may be due to a progressive increase of the pressure within the sinus caused by obstruction (polyp or tumor). But Ricci JA et al concluded that there might be more than one potential etiology. ${ }^{5}$

Expansion of the frontal sinus may directed outward and inward that is towards intracranial. The clinical presentations typically correspond to which structures are involved. It may involve the surrounding structures like orbit, nose or other sinuses. The most common clinical symptoms are ocular disturbances like vague and diplopia, local pain, headache, aesthetic complaints like frontal brow elevation, frontal bossing and distortion of facial morphology leads to cosmetic disturbances.

\section{Conclusion}

With the expansion of the modern technologies, we can standardize the clinical evaluation. A plain radiograph is sufficient to study PDF yet it is sensible to have a CT scan of paranasal sinuses done to rule out not only gross bony pathology or deformity but also to identify the number and location of the sinuses involved. It also give clear picture of etiology if any involved. Hence, a detailed anatomical and morphometric knowledge of the region is necessary to perform the successful surgeries and outcome.

\section{References}

1. Tellado MG, Mendez R, Lopez-Cedrun JL, Fantini M, Martín-Sastre R, Somoza I, Liras J, Vela D. Pneumosinus dilatans of the frontal and ethmoidal sinuses: case report. Journal of Cranio-Maxillofacial Surgery. $2002 \mathrm{Feb}$ 1;30(1):62-4.

2. Meyes WP. Mittheilung eines Falles vermatchlicher Pneumatocoele des Sinus frontalis Montatsschr Ohrenheilkd. 1898;32:467-9.

3. Benjamins, LE: Pneumosinus frontalis dilatans. Acta Otolaryngol. 1918;1:412-22.

4. Afroze KH, Suresh BS, Lakshmiprabha S. Pneumosinus Dilatans Frontalis- A Rare Anatomical Variation of Frontal sinus. International journal of Anatomy, Radiology and Surgery. 2017 July;6(3):AC01-2.

5. Ricci JA. Pneumosinus Dilatans: Over 100 Years without an Etiology. Journal of Oral and Maxillofacial Surgery. $2017 \mathrm{Feb} 21$

6. Knapp FB and Klenzner T, Pneumocele as a rare differential diagnosis in trigeminal irritation. Am J Otolaryngol 2003;21:236- 38.

7. Kalpana Purohit, Ankita Purohit, Ramesh Palanisamy. Pneumosinus Dilatans: A Cadaveric Case Report. Int J Med Res Prof. 2016,2(1);89-91.
8. Urken ML, Som PM, Lawson W, Edelstein D, Weber AL, Biller HF: Abnormal large frontal sinus. II. Nomenclature, pathology and symptoms. Laryngoscope. 1987;97:606-11.

9. Duque CS, Casiano RR. Surgical Anatomy And Embryology Of The Frontal Sinus. In: Kountakis S, Senior BA, Draf W (2005) The Frontal Sinus. Springer.

10. Rubira-Bullen IRF, Rubira CMF, Sarmento VA, Azevedo RA. Frontal sinus size on facial plain radiographs. - J Morphol Sci., 27, 2010, No. 2,77-81.

11. Thimmasettaiah NB, Chandrappa RG, Sukumari S. Pmeumosinus Dilatans Frontalis: A case report. Translational Biomedicine. 2014;5(11):1-5.

12. Tellado MG, Mendez R, Lopez-Cedrun JL, Fantini M, Martín-Sastre R, Somoza I, Liras J, Vela D. Pneumosinus dilatans of the frontal and ethmoidal sinuses: case report. Journal of Cranio-Maxillofacial Surgery. 2002 Feb 1;30(1):62-4.

13. Appelt EA, Wilhelmi BJ, Warder DE, et al: A rare case of pneumosinus dilatans of the frontal sinus and review of the literature. Ann Plast Surg 43:653,1999. 